\title{
Fennel Oil
}

National Cancer Institute

\section{Source}

National Cancer Institute. Fennel Oil. NCI Thesaurus. Code C65657.

The oil extracted from the seeds of Foeniculum vulgare. Fennel oil is commonly used to treat disorders of the digestive system. 